\title{
Blood alcohol levels in acute elderly admissions to hospital
}

\author{
N.D. Penn, O.J. Corrado, L.J. Pitchfork ${ }^{1}$, R.T. Evans ${ }^{1}$ and B.H. Mascie-Taylor \\ Departments of Medicine (Elderly) and 'Biochemistry, St James's University Hospital, Beckett Street, \\ Leeds LS9 7TF, UK.
}

\begin{abstract}
Summary: Blood alcohol levels were estimated in 141 patients admitted acutely over a one month period to a geriatric unit. Only four $(2.8 \%)$ had alcohol detectable in their blood. The levels were low, suggesting that alcohol intoxication is not a major factor in the admission of the elderly to hospital.
\end{abstract}

\section{Introduction}

Studies on alcohol and the elderly have concentrated mainly on the prevalence of alcoholism. Few have studied alcohol intake and its consequences. The Office of Population Censuses and Surveys found that the rate of abstinence increased and the rate of heavy drinking decreased with age. ${ }^{1}$ This does not mean that alcohol intake ceases to be of clinical importance in the elderly who are at increased risk from its adverse effects. ${ }^{2}$ The aim of this study has been to assess how frequently alcohol could be detected in the blood of elderly patients admitted acutely to hospital.

\section{Patients and method}

One hundred and forty one patients (29 male, 112 female, median age 82.7 years) admitted acutely to our department over a 28 -day period were studied and this represented $84.6 \%$ of all acute admissions. The department operates an age related policy, admitting patients over the age of 65 directly from the community and unselected medical patients over 80 years from the Accident and Emergency department. Blood was taken as soon as possible following admission (range 10-145 minutes, median 37.5 minutes) and patients asked when they had taken their last alcoholic drink. The following day a more detailed questionnaire was completed. This elicited the cause of admission, social circumstances and alcohol intake. Assessment of alcohol consumption was based on how frequently alcohol was drunk. Four groups of subjects could be identified; abstainers (were defined as those who had not taken alcohol in the last year), infrequent drinkers (defined as those who took alcohol less than once a week), weekly drinkers and daily drinkers.

Correspondence: N.D. Penn, M.B., M.R.C.P.

Accepted: 28 September 1988
When the information could not be obtained from the patient the carer was interviewed. Tables I and II illustrate the type of residences from which patients were admitted and the reasons for admission.

Alcohol was measured using packed column gas/ liquid chromatography (Carbowax 400) with flame ionization detection.

\section{Results}

Alcohol was detected in the blood of only four $(2.8 \%)$ patients and then only at low levels $(3,4,10$ and $12 \mathrm{mg} / \mathrm{dl}$ ). Two of these patients (one with a chest infection and the other with back pain following a vertebral collapse) claimed to have taken the alcohol for 'medicinal' reasons after the onset of the symptoms for which they were later admitted to hospital. One patient admitted following a fall had been drinking previously. The fourth patient, who had suffered a myocardial infarction, denied any alcohol intake. Sixty eight $(42 \%)$ of patients took alcohol at least occasionally (Table III) but none admitted to drinking large quantities.

\section{Discussion}

The metabolism of alcohol alters with age. There is a decrease in the efficiency of the liver enzymes responsible for its metabolism ${ }^{3}$ and an increase in the ratio of fat to lean body mass. This results in the elderly having a higher blood alcohol than younger people for a given dose. ${ }^{4}$ Additionally there is an increase in sensitivity to central nervous system (CNS) depressing drugs with age. Thus moderate doses of alcohol are more likely to cause lowered levels of cognition in the elderly. This problem is compounded when other CNS depressants

C) The-Fellowship of Postgraduate Medicine, 1989 
Table I Type of residence from which patients were admitted

\begin{tabular}{lcc}
\hline & Patient number & $\%$ \\
\hline Own home & 65 & 46 \\
Part III & 28 & 20 \\
Nursing home & 27 & 19 \\
Family & 16 & 11 \\
Residential & 5 & 4 \\
\hline
\end{tabular}

Table II Reason for admission

\begin{tabular}{lcc}
\hline & Patient number & $\%$ \\
\hline Falls & 36 & 26 \\
Infection & 28 & 20 \\
Cardiac & 21 & 15 \\
Confusion & 20 & 14 \\
Stroke & 16 & 11 \\
Miscellaneous & 20 & 14 \\
\hline
\end{tabular}

Table III Frequency of questionnaire-determined alcohol intake

\begin{tabular}{|c|c|c|c|c|c|}
\hline & Abstainers & $\begin{array}{c}\text { Infrequent } \\
\text { drinkers }\end{array}$ & Weekly & Daily & $\begin{array}{c}\text { Number of } \\
\text { subjects }\end{array}$ \\
\hline Male (\%) & 38 & 17 & 31 & 14 & 29 \\
\hline Female (\%) & 55 & 21 & 24 & 0 & 112 \\
\hline
\end{tabular}

\section{References}

1. Office of Population Censuses and Surveys. Drinking behaviour and attitudes in Great Britain. H.M.S.O., London, 1983.

2. Vogel-Sprott, M. \& Barratt, P. Age, drinking habits and the effects of alcohol. J Stud Alcohol 1984, 45: 517.

3. Raskind, M. \& Eidorfer, C. Psychopharmacology of the aged. In: Drug Treatment of Mental Disorders. Raven Press, New York, 1976. are being taken. ${ }^{3}$ Alcohol is said to exacerbate common underlying medical conditions, for example by reducing respiratory drive in patients with chronic obstructive airways disease. It may also mask the symptoms of angina in patients with ischaemic heart disease. In patients with pre-existing impaired cardiac function cardiac output has been shown to decrease after as little as one drink. ${ }^{5}$

It has been suggested that some cases of hospital admission may be precipitated by the intake of alcohol. In America it has been estimated that a minimum of $10 \%$ of those individuals who come to emergency rooms for alcohol-related problems are aged 60 and over. ${ }^{6}$ In our study, although $68 \%$ of patients admitted to drinking alcohol socially, only $2.8 \%$ had alcohol detectable in the blood at the time of admission (and then only at low levels). Blood alcohol falls on average by $15 \mathrm{mg} / 100 \mathrm{ml} /$ hour and our results may reflect the time taken for the patient to reach hospital. However, it seems unlikely that alcohol consumption is a major cause of admission to hospital in the elderly.

4. Vestal, R.E., McGuire, E.A., Tobin, J.D., Andres, R., Norris, A.H. \& Mezey, E. Aging and ethanol metabolism. Clin Pharmacol Ther 1977, 21: 343.

5. Gould, L., Zahir, M. \& Demartino, A. Cardiac effects of a cocktail. JAMA 1971, 239: 1799-1802.

6. Schuckit, M.A. A clinical review of alcohol, alcoholism and the elderly patient. J Clin Psychiatry 1982, 10: 396-399. 